patients with recurrent unexplained falls and syncope, and $82 \%$ of this group benefit from intervention. ${ }^{2}$ Simple faints are uncommon in elderly people, partly because of their altered baroreflex sensitivity. Treatment with a vasodilator is the commonest cause of vasovagal syncope, and symptoms may be modified or abolished by a change in treatment.

If carotid sinus massage produces an importan reproducible asystolic response this is not normal and in symptomatic patients requires physiological pacing to abort recurrent symptoms. ${ }^{4}$ Slowing of the heart rate of greater than 3 seconds during carotid sinus massage does not occur in asymptomatic elderly people. ${ }^{5}$ The carotid sinus syndrome is an underdiagnosed cause of dizziness, falls, and syncope, ${ }^{3}$ and cardiac pacing will abort syncopal episodes in most cases, although dizziness may persist because of persistent hypotensive features. ${ }^{4}$

ROSE ANNE KENNY

Department of Medicine (Geriatric Medicine)

Royal Victoria Infirmary,

Newcastle upon Tyne NE1 4LP

1 Petch H. Syncope. BMF 1994;308:1251-2. (14 May.)

2 McIntosh S, da Costa D, Kenny RA. Outcome of an integrated approach to the investigation of dizziness, falls and syncope in elderly patients referred to a syncope clinic. Age Agein 1993;22:53-8.

3 McIntosh S, Lawson J, Kenny RA. Clinical characteristic of cardioinhibitory vasodepressor and mixed carotid sinus syndrome. Am F Med 1993;95:203-8.

4 Morley CA, Perrins EJ, Grant P, Chan SL, McBrien DJ, Sutton R. Carotid sinus syncope treated by pacing: analysis of R. Carotid sinus syncope treated by pacing: analysis of
persistent symptoms and role of atrioventricular sequential persistent symptoms and role of

5 McIntosh S, Lawson J, Kenny RA. Heart rate and blood pressure responses to carotid sinus massage in healthy elderly subjects. Age Ageing 1994;23:57-61.

\section{Vulvovaginal candidiasis}

EDIToR,-Susan M Sawyer and colleagues state that they report the rate of vulvovaginal candidiasis in young women with cystic fibrosis. ${ }^{1}$ This, however, is not justified by the evidence presented rather, what they report is the rate of genital symptoms.

The authors do not state whether an affirmative answer given to the question "Have you had thrush infections (candida infection)?" meant that a microbiological diagnosis had been made or that certain symptoms had been experienced by the patient. If it meant that certain symptoms had been experienced, what were they? Self diagnosis of vaginal thrush is unsatisfactory as this term may be used by patients to describe a wide variety of symptoms not always relating to candidal infection (or any genital infection, for that matter.)

Although the answers given by the patients may not truly reflect the incidence of vaginal candidiasis, this report highlights importan morbidity that, as the authors indicate, needs to be addressed. Given that this is a group of young sexually active women, however, advice should be given not only about candidiasis but about sexual health in general.

CHRISTINE M BATES

Department of Genitourinary Medicine,

Royal Liverpool University Hospital

Royal Liverpool U
Liverpool L7 8XP

1 Sawyer SM, Bowes G, Phelan PD. Vulvovaginal candidiasis in young women with cystic fibrosis. BMf 1994;308:1609. (18 June.)

\section{Authors' reply}

EDITOR,-Christine Bates appropriately raises the concern that the high rate of self-reported vulvovaginal candidiasis that we recently described could be explained by a variety of disorders. We were surprised by the high rates reported and subsequently telephoned a quarter of the participants for clarification of their response to this question. All of those who had reported vulvovaginal candidiasis had obtained microbiological confirmation on at least one occasion.

Recently, 54 of 66 adult women with cystic fibrosis $(82 \%)$ who attend Boston Children's Hospital cystic fibrosis clinic were investigated (unpublished data). In response to the question, "Have you ever had an episode of vulvovaginal candidiasis (vaginal yeast infections, vaginal thrush, vaginal candida)?" $91 \%$ reported they had experienced at least one episode and 35\% reported very frequent infections (the two most severe categories). These figures are similar to, but slightly higher than, the data we recently reported ( $80 \%$ and $23 \%$ respectively). Two thirds of the Boston women with a history of self reported vulvovaginal candidiasis had microbiological confirmation on at least one occasion, and four women $(8 \%)$ reported other vaginal infections (gardnerella, trichomonas (2), and vaginal warts). About half the participants reported an increase in vulvovaginal candidiasis when they changed oral antibiotics or started intravenous antibiotics.

The lack of recognition of these vaginal symptoms suggests that health care professionals have failed to notice the broader health concerns of these women beyond the recognised morbidities of cystic fibrosis. We strongly agree with Bates that advice to this group of women should be given not only about candidiasis but about reproductive and sexual health in general. As we have recently described, however, this is not straightforward. ${ }^{2}$ What little information is currently available (such as the risks of pregnancy or the risk of having a child with cystic fibrosis) seems not to be adequately communicated to, or understood by, this group of patients, and in other cases the required information is simply not available (such as how cystic fibrosis affects fertility).

\section{S M SAWYER}

Physiology Program, Research fellow

Harvard School of Public Health,

Boston MA 02115,

USA

G BOWES

Professor of adolescenthealth

P D PHELAN

Royal Children's Hospital,

Stevenson professor of $p$

Melbourne,

Australia

1 Sawyer SM, Bowes G, Phelan PD. Vulvovaginal candidiasis in young women with cystic fibrosis. $B M 7$ 1994;308:1609.

2 Sawyer SM, Phelan PD, Bowes G. Reproductive health in young women with cystic fibrosis knowledge, behaviour and attitudes. $₹$ Adol Health (in press)

\section{Managing patients who refuse blood transfusions}

\section{Register of willing consultants exists}

EDrTor,-Commenting on the article by Simon Finfer and colleagues concerning two Jehovah's Witnesses who refused blood transfusions, Arabinda Saha and Max Elstein suggest the establishment of a register of consultants willing to accept such patients so that referral and appropriate management can be undertaken.

For many years Jehovah's Witnesses have themselves researched and maintained such a confidential register, names from which are released to bona fide applicants on a case by case basis. The register contains the names of some 2400 consultants in Britain and is part of a worldwide listing of more than 45000 specialists. Any doctor who wishes to refer a patient who is a Jehovah's Witness or to consult with a colleague experienced in medical or surgical management not entailing blood transfusion is welcome to contact one of the Witnesses' hospital liaison committees, now established in 36 locations in Britain and in over 1000 cities around the world.

JW A BRACE

Deputy hospital information coordinator

Watch Tower Bible and Tract Society of Pennsylvania

London NW7 1RP

1 Finfer S, Howell S, Miller J, Willett $\mathrm{K}$, Wilson-MacDonald J, Wilson DH, et al. Managing patients who refuse blood transfusions: an ethical dilemma. $B M \mathcal{F}$ 1994;308:1423-6. (28 May.)

Saha A, Elstein M. Managing patients who refuse blood transfusions. $B M F$ 1994;309:125. (9 July.)

\section{Will consent if confidentiality is maintained}

EDITOR,-The article by Simon Finfer and colleagues highlighted the practical dilemmas associated with treating Jehovah's Witnesses. The stand of Jehovah's Witnesses concerning blood transfusion is based on an interpretation of certain Levitical texts (Leviticus 7:26-7 and 17:10-4). Should a Witness be given a transfusion, the same texts allow for the individual to be "cast out" ("disfellowshipped") from the community. Disfellowshipping (a combination of excommunication and shunning) can be a severe sanction for the individual.

In addition there is a considerable grey area concerning protein products, ${ }^{2}$ and the decision whether or not to accept these is one of individual conscience. Should a coagulopathy develop, it is helpful to establish which clotting factors (or combinations) would be acceptable. A recent patient was prepared to accept plasma protein fraction, cryoprecipitate, and individual factors, but not fresh frozen plasma. The Jehovah's Witnesses Hospital Liaison Committee has been helpful in explaining the theological and doctrinal differences between various products to their members.

I have anaesthetised Witnesses for cardiac surgery for several years. It is my practice to tell each patient that any decision on whether they wish to receive blood or products will be respected totally and will remain absolutely confidential, and that no clinical information concerning treatment will be divulged in any circumstances.

As long as strict confidentiality could be maintained, several Witnesses have said that they would accept blood or products rather than die of anaemia or a coagulopathy, in spite of having signed a special consent form for Jehovah's Witnesses which forbids the use of blood.

P D COOPER

Freeman Hospital,
Newcastle upon Tyne NE7 7DN

Consultant car

1 Finfer $S$, Howell $S$, Miller J, Willetr $K$, Wilson-MacDonald J, Wilson $\mathrm{DH}$, et al. Managing patients who refuse blood Wilson DH, et al. Managing patients who refuse blood (28 May.)

2 Questions from readers. Watchtower 1978 June 15:30-1.

\section{Cardiopulmonary resuscitation}

EDITOR,-In 1991 the chief medical officer promulgated the health service commissioner's comments on the processes involved in identifying the resuscitation status of patients in hospital. Since then my department has audited its practices and introduced changes in an effort to follow the suggestions recommended. We find that consultant staff review patients at least twice a week and inform the nursing staff of patients' resuscitation status during visits to the ward. Despite various attempts to find a practicable and safe way to document decisions in the notes, however, we have encountered major difficulties. If the decisions are 